\title{
A pictorial essay of the most atypical variants of the vermiform appendix position in computed tomography with their possible clinical implications
}

\author{
Anna Zacharzewska-Gondek ${ }^{A, B, C, D, E, F}$, Agata Szczurowska ${ }^{A, B, C, D, E}$, Maciej Guziński ${ }^{A, B, C, D}$, Marek Sąsiadek ${ }^{A, D, E}$, \\ Joanna Bladowska ${ }^{A, B, C, E}$
}

Department of General and Interventional Radiology and Neuroradiology, Wroclaw Medical University, Wroclaw, Poland

\section{Abstract}

Purpose: The tip of the appendix may be located in various areas of the abdominal cavity due to its variable length and/or the changeable position of the caecum. Although in the case of an atypical position the tip is usually located behind the caecum, there are possible locations that occur very rarely. Therefore, in the case of appendicitis the symptoms may lead to the wrong diagnosis. The aim of this study is to present the most atypical locations of the tip of the appendix found on CT (computed tomography) scans and thus help to avoid misdiagnoses.

Imaging findings: The most unusual locations of the tip of the appendix found in healthy subjects included: left inferior quadrant, along the lower edge of the liver near the gallbladder and the right kidney, the tip touching the duodenum, the rectum or appendages, and a long appendix located in the scrotum as the content of a hernia. In these positions, appendicitis may mimic acute diverticulitis, cholecystitis, duodenal ulcer, duodenitis, enteritis, or adnexal or testis pathologies.

Conclusions: It is important to be aware of atypical locations of the appendix because appendicitis in an unusual area may mimic other acute abdominal diseases and delay the proper treatment.

Key words: vermiform appendix, anatomical variants, atypical appendicitis, computed tomography.

\section{Introduction}

Appendicitis is one of the most frequent causes of acute abdomen and usually requires urgent surgical intervention in order to avoid severe complications. The vermiform appendix located in the atypical abdominal region may lead to a delay in proper treatment due to symptoms mimicking other diseases. The aim of this study was to present unusual locations of the tip of the appendix and to discuss their clinical implications.

The vermiform appendix is a diverticulum of the caecum, which usually lies in the right lower quadrant of the abdomen [1]. However, the appendix is believed to be the most variable abdominal organ because there are many possible configurations of its location [2-4]. The base of the appendix is usually located in the posteromedial aspect of the caecum (about $2 \mathrm{~cm}$ under the ileocecal valve, in the confluence of three taenias, in McBurney's point) [1], while the appendix tip can be found in various sites [2-5]. The following positions were distinguished $[3,6]$ :

- retrocaecal (or retrocolic when long) - appendix situated posteriorly and superiorly to the caecum or ascending colon,

- paracaecal - appendix located laterally to the caecum and ascending colon,

- subcaecal - under the caecum,

- pelvic or descending intraperitoneal - appendix directed inferiorly, 'pointing' the pelvis,

\section{Correspondence address:}

Anna Zacharzewska-Gondek, MD, Department of General and Interventional Radiology and Neuroradiology, Wroclaw Medical University, 213 Borowska St.,

50-556 Wrocław, Poland, e-mail: aniazacha@gazeta.pl

Authors' contribution:

A Study design · B Data collection · C Statistical analysis · D Data interpretation · E Manuscript preparation · F Literature search · G Funds collection 
- pre-ileal and post-ileal - located anteriorly and superiorly or posteriorly and superiorly to the ileum.

The most frequent location of the appendix has been a controversial issue - in several studies conducted on cadavers or during laparoscopic surgery, retrocaecal $[2,3,6]$ or pelvic $[4,7]$ position were the most common findings. It has been suggested that the location and length of the vermiform appendix may depend on age, gender, race, or other demographic factors $[2,4,7]$. The length of the vermiform appendix ranges between $1.0 \mathrm{~cm}$ and $27 \mathrm{~cm}$, with an average length of about 7-11 cm [1-5,7]. Moreover, the appendix is one of the most mobile viscera because of its mesentery, which is called the mesoappendix. The position of the appendix may change during life, particularly after surgical intervention into the abdomen or pelvis $[3,7]$. Congenital atypical location of the vermiform appendix may result from developmental disturbances leading to the abnormally situated caecum due to nonrotation, malrotation, sessile caecum, or others [1].

We present the most unusual locations of the tip of the appendix found by chance on computed tomography (CT) scans in 13 patients who have been examined in our hospital between December 2014 and November 2017 for other reasons and in whom appendiceal position was reported as a CT finding.

\section{Imaging findings}

In three patients the appendix was located in the left inferior abdominal quadrant due to midgut nonrotation with left-sided caecum (Figure 1) or situs inversus (Figure 2). In five patients the subhepatic location of the appendix along the lower edge of the liver and/or next to the right kidney was observed; these patients had a long retrocaecal and consequently retrocolic appendix (Figure 3) or a high position of the caecum (Figures 4 and 5). In two cases the tip of the long retro-ileal appendix was visualised next to the descending part of the duodenum (Figure 6) or even the horizontal part of duodenum in the midline (Figure 7). We also found a long appendix crossing the right ureter (Figure 8). In such cases it may continue to encompass appendages in women (Figure 9). Two patients were found with a pelvic-located appendix reaching the wall of the rectum (Figures 10 and 11). There was one case of a long pelvic appendix ending in the scrotum as the content of an inguinal hernia (Figure 12). We noted that any surgery involving the abdomen or pelvis may change the position of the vermiform appendix, such as a case after a prostatectomy, as presented in Figure 13.

\section{Discussion}

\section{Embryonic development}

The variations of the appendix position usually result from a complicated and changeable embryonic develop- ment of the caecum $[1,8,9]$ and/or the variable length of the appendix $[5,10]$.

The development of the caecum and the vermiform appendix is related to the midgut rotation between the $6^{\text {th }}$ and $10^{\text {th }}$ gestational week. As a result of the rotation the caecum bud is translocated to the right side of the upper abdominal cavity beneath the liver. Afterwards it grows out inferiorly (a so-called descensus of the caecum). Finally, the caecum and the appendix are positioned in the right iliac fossa. Due to asymmetrical growth of the lateral part of the caecum, the vermiform appendix is usually located medially, upwardly, and dorsally; in this position it remains free after fixation of the caecum [1]. The retrocaecal position of the vermiform appendix seems to be connected with descensus of the caecum, when the appendix can bend behind the caecum, and it consequently remains fixed in this position [6].

Importantly, there are a lot of developmental disturbances during midgut rotation, leading to atypical positions of the caecum, including inter alia nonrotation with the left-sided colon and caecum, malrotation with caecum below the pylorus, subhepatic caecum due to lack of descensus, and mobile caecum resulting from lack of fixation in the right iliac fossa [1]. Subhepatic position of the vermiform appendix may be caused not only by arrested caecal descent but also by long, retrocolic appendix, whose base is situated in a normal position in the right iliac fossa [5].

\section{Imaging techniques for visualisation of the vermiform appendix}

The normal vermiform appendix and its variants can be visualised by various imaging modalities noninvasively. Ultrasound is characterised by relatively poor accuracy in finding the unchanged vermiform appendix for a few reasons - this method is highly dependent on the experience of the operator and the patient's constitutional factors like body mass index, abdominal wall thickness, and amount of intraluminal gas in bowel loops. According to data of Yabunaka et al. an assessment of the unchanged vermiform appendix positions in the ultrasound may be underestimated, particularly regarding retrocaecal position, which was sonographically found only in $9.5 \%$ of cases [11]. Otherwise, computer tomography is an excellent imaging technique in the evaluation of the normal vermiform appendix because of its very good spatial resolution in any desired plane, avoiding most of the ultrasound-dependant limitations [12]. In magnetic resonance imaging the normal vermiform appendix may be recognisable as hypointense in T1-weighted and T2-weighted, thin-walled tubular structure [13].

\section{Diagnostic imaging of appendicitis}

Inflammation of the typically located appendix usually begins with acute pain around the umbilicus. The pain 


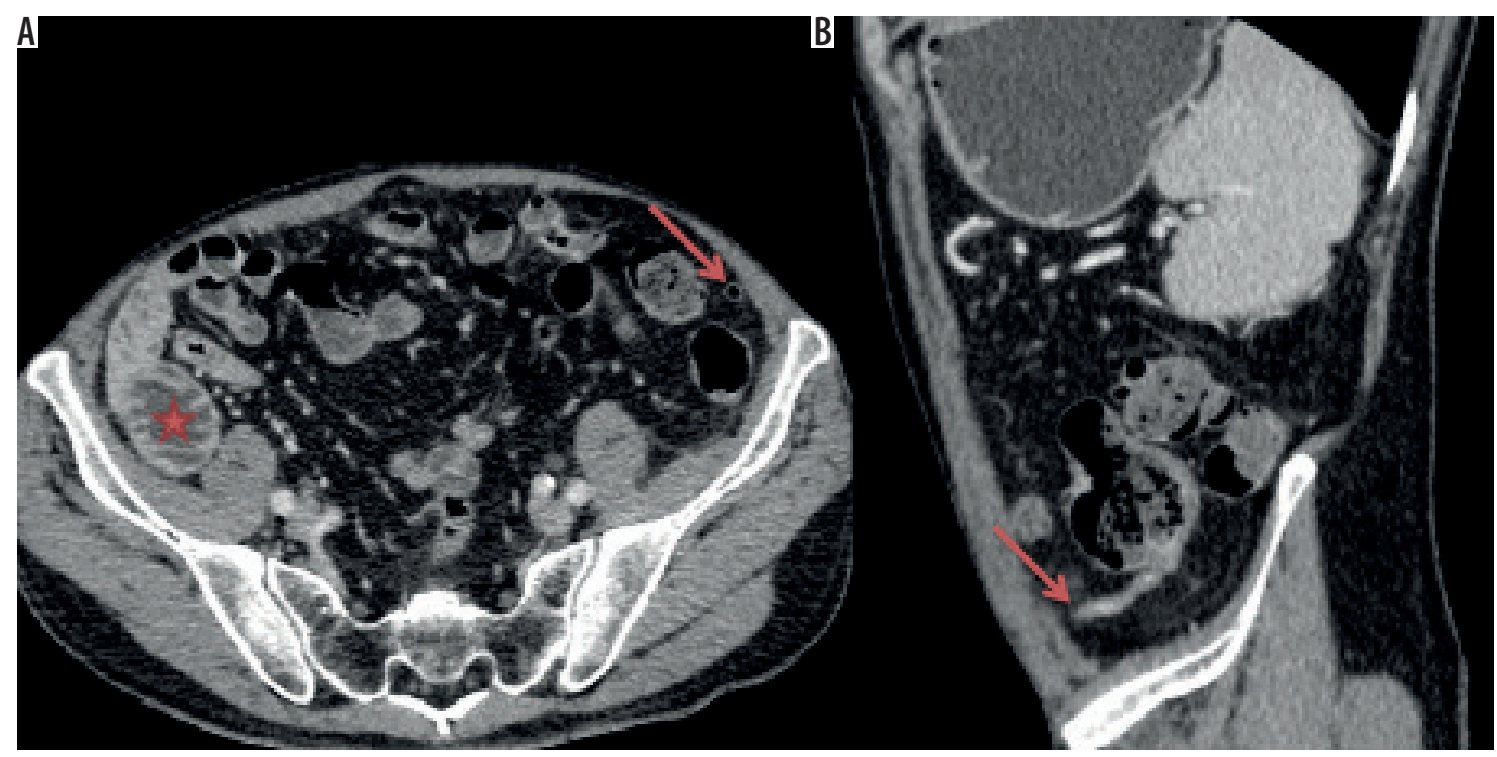

Figure 1. Axial CT scan (A) and sagittal CT reformation (B) of a patient with midgut malrotation - jejunum (star) is visualised on the right side, the caecum with the vermiform appendix (arrow) is located on the left side. The base of the appendix is visible atypically posterolaterally, length of the appendix about $8.5 \mathrm{~cm}$

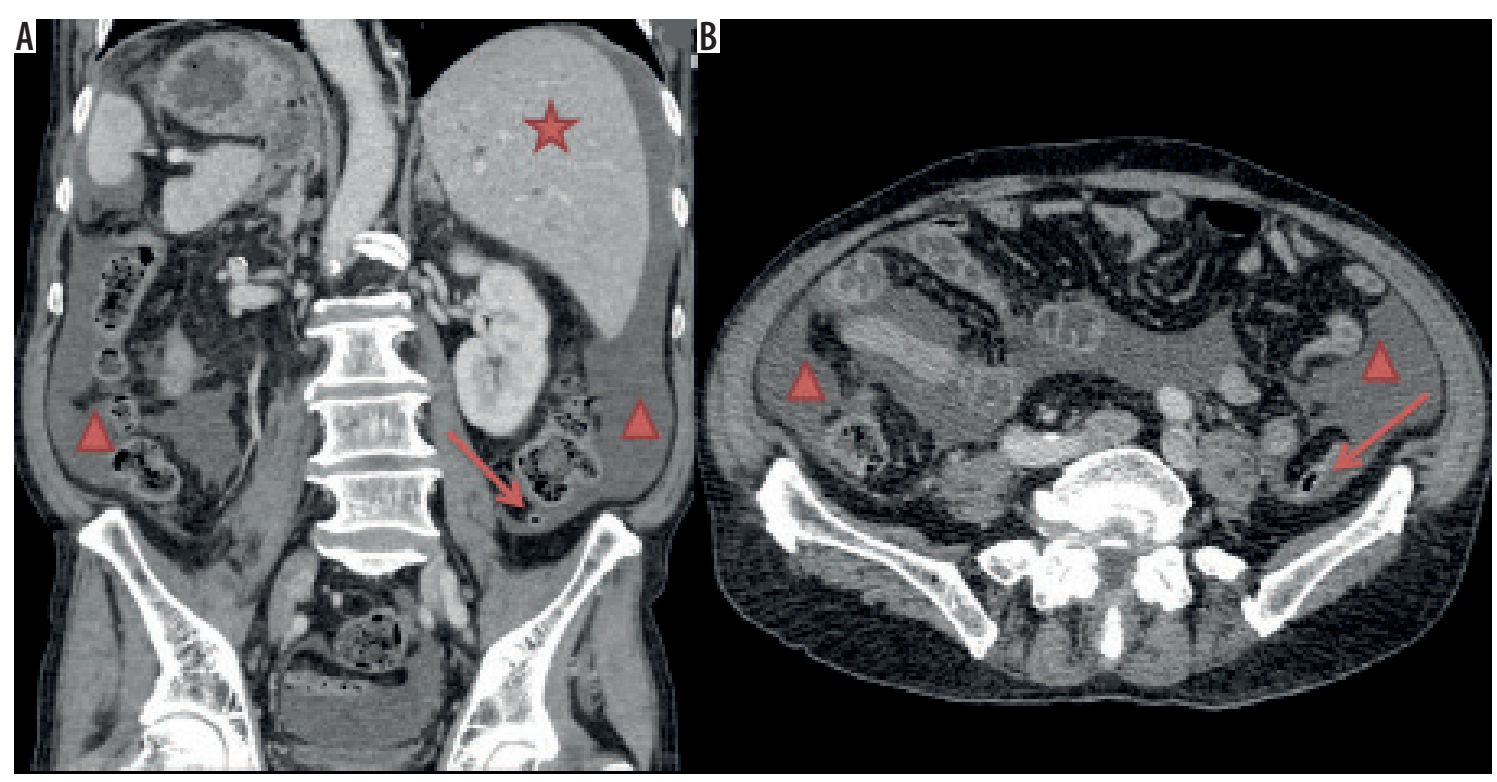

Figure 2. Coronal CT reformation (A) and axial CT scan (B) of a patient with situs inversus and acute pancreatitis (fluid - triangle). The liver (star) and caecum with the vermiform appendix (arrow) are located on the left side. The appendix is in a subcaecal position with normal length about $6.2 \mathrm{~cm}$
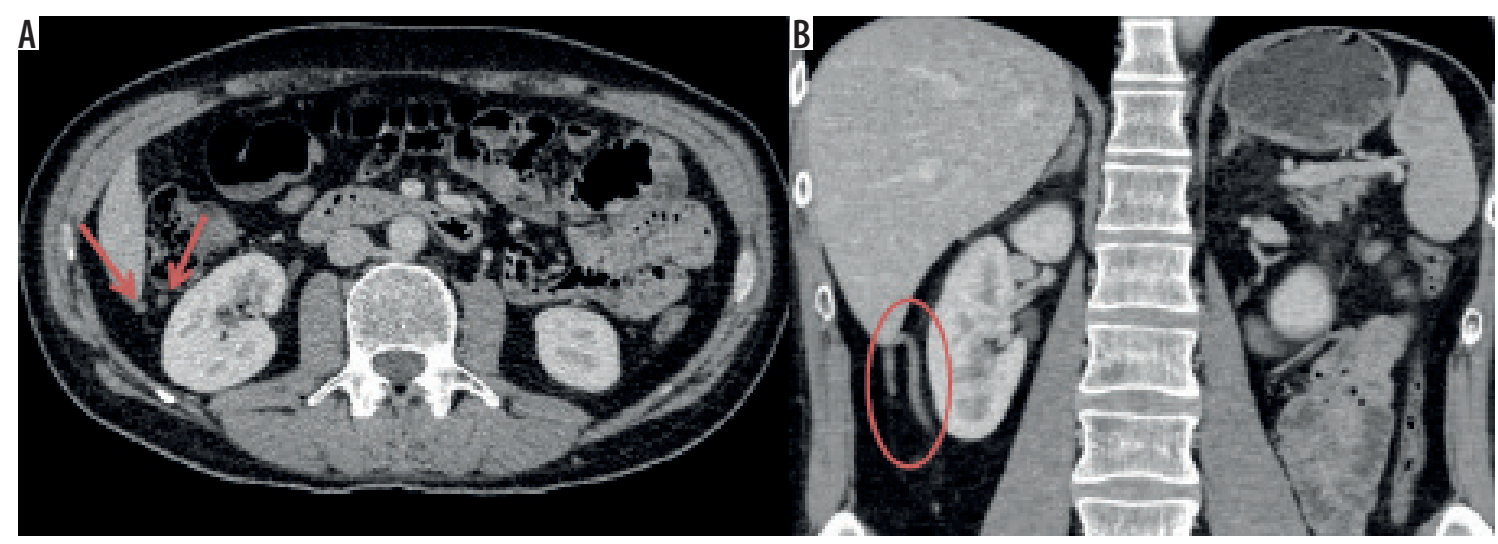

Figure 3. Axial CT scan (A) and coronal CT reformation (B) show an approximately 12.7-cm-long retrocolic appendix located next to the lateral aspect of the right kidney (circle) and near the lower edge of the liver (arrows). The caecum in this patient was situated in the normal position (not shown) 


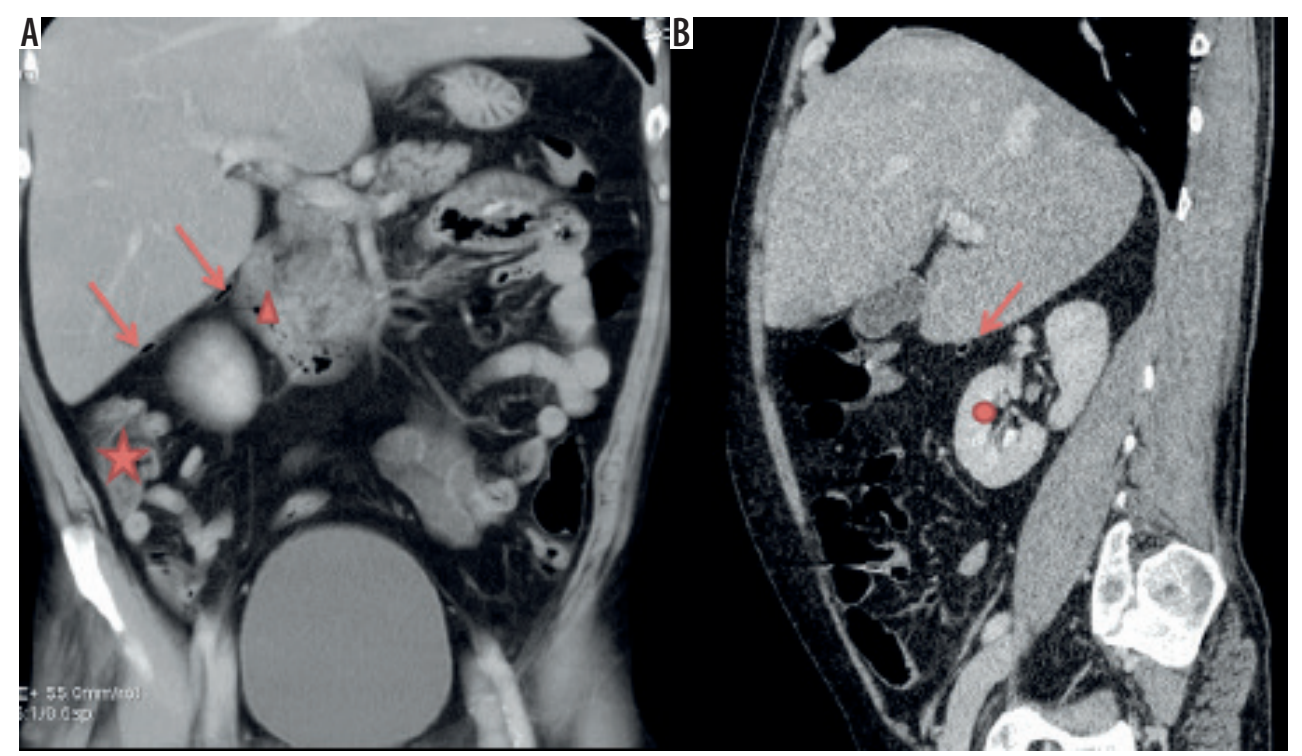

Figure 4. Coronal (A) and sagittal (B) CT reformations of a patient with a high position of the caecum (star) and a 9.5-cm-long vermiform appendix (arrow) located along the lower edge of the liver, next to the right kidney (circle), and the descending part of the duodenum (triangle)

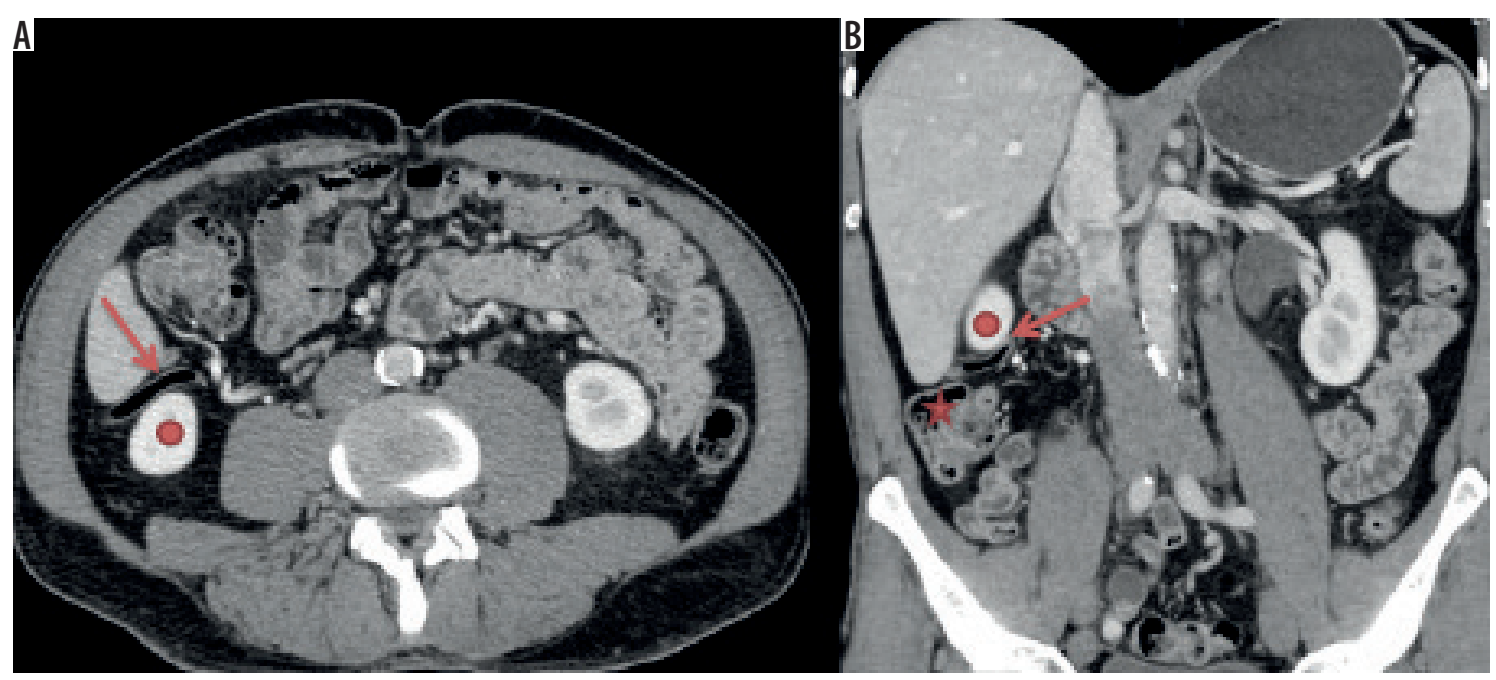

Figure 5. Axial CT scan (A) and coronal CT reformation (B) of a patient with a high position of the caecum (star) and an approximately 13.8-cm-long vermiform appendix (arrow) located near to the lower edge of the liver and the right kidney (circle)

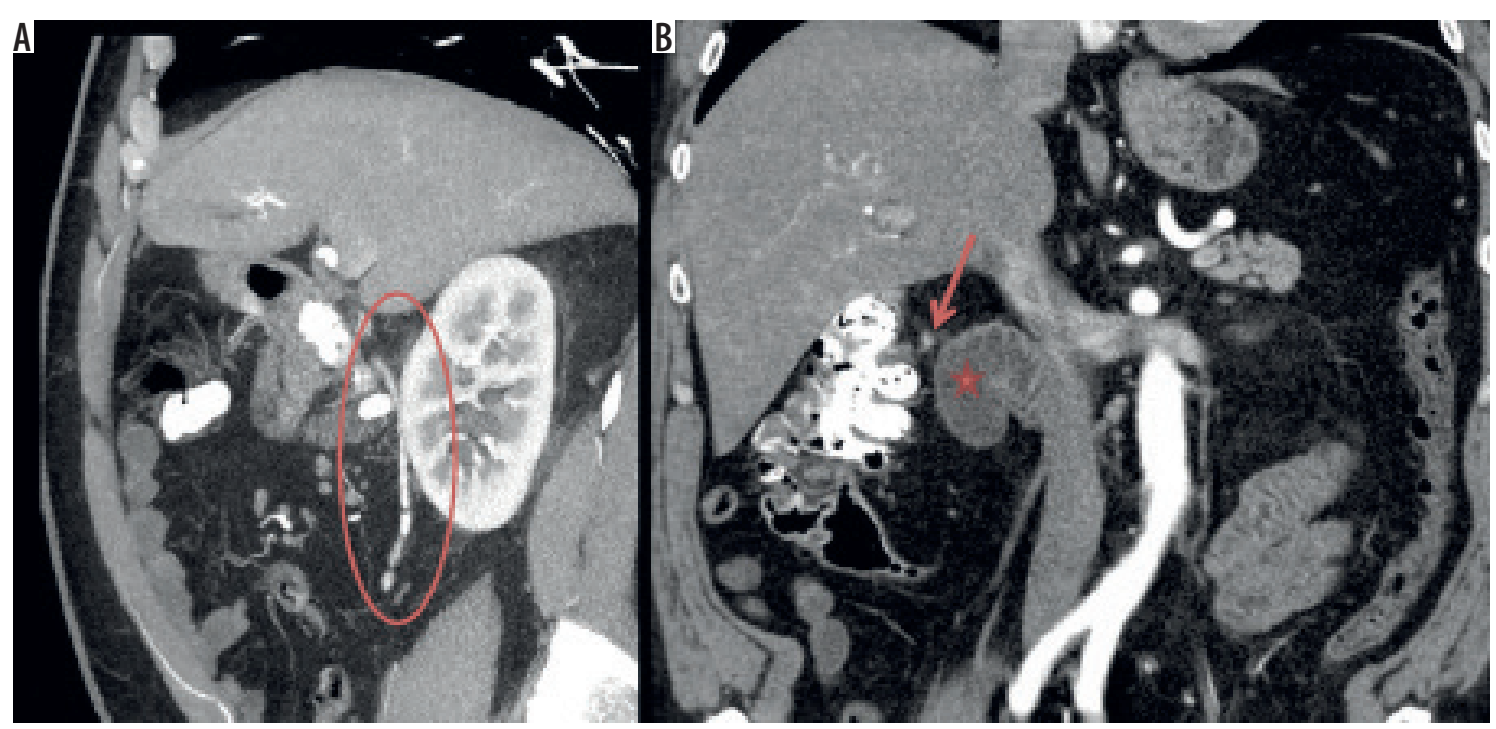

Figure 6. Sagittal (A) and coronal (B) CT reformations of a patient with a long (approximately $13.8 \mathrm{~cm}$ ), postileally situated, barium-filled vermiform appendix (circle), located medially and anteriorly to the right kidney and its tip (arrow) reaches the descending part of the duodenum (star) 


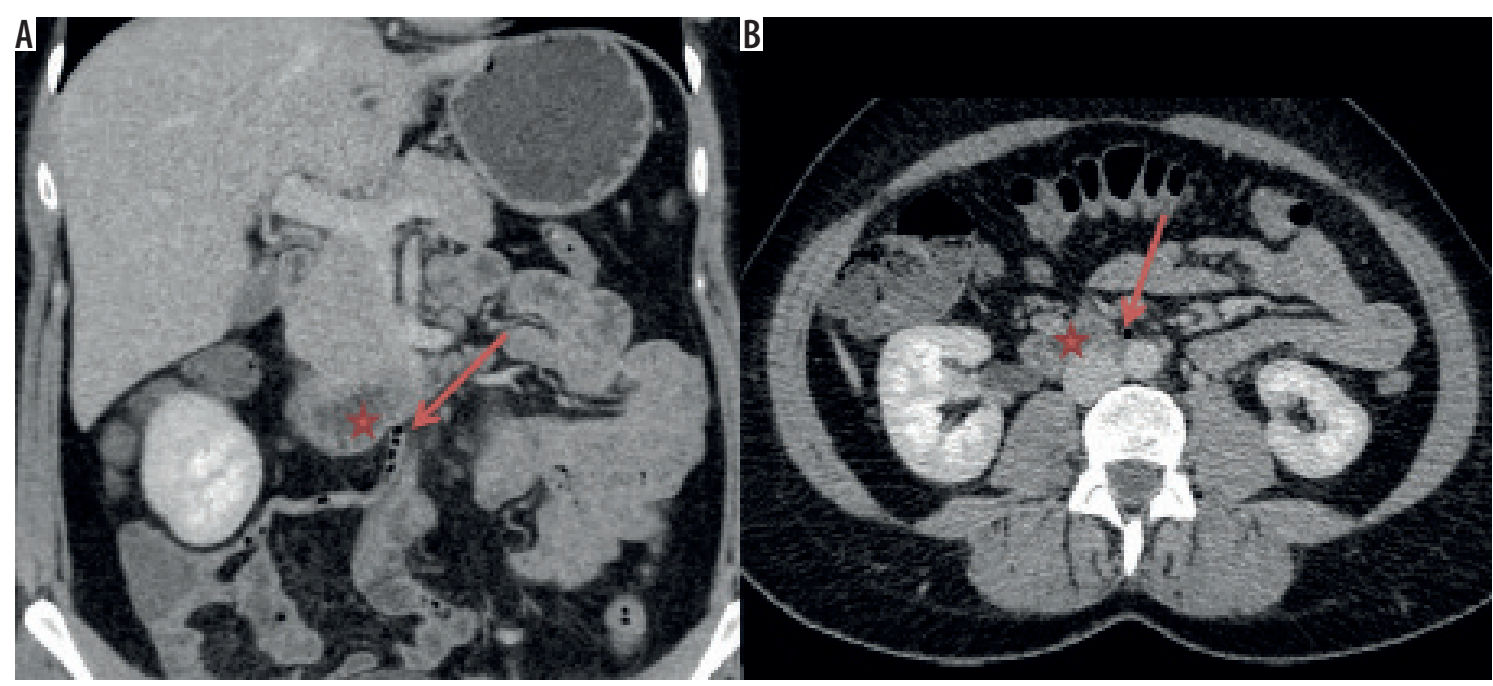

Figure 7. Coronal CT reformation (A) and axial CT scan (B) of a patient with an 11.1-cm-long postileally situated vermiform appendix, whose distal part is located medially in the mesogastric area and the tip (arrow) touches the wall of the horizontal part of the duodenum (star)

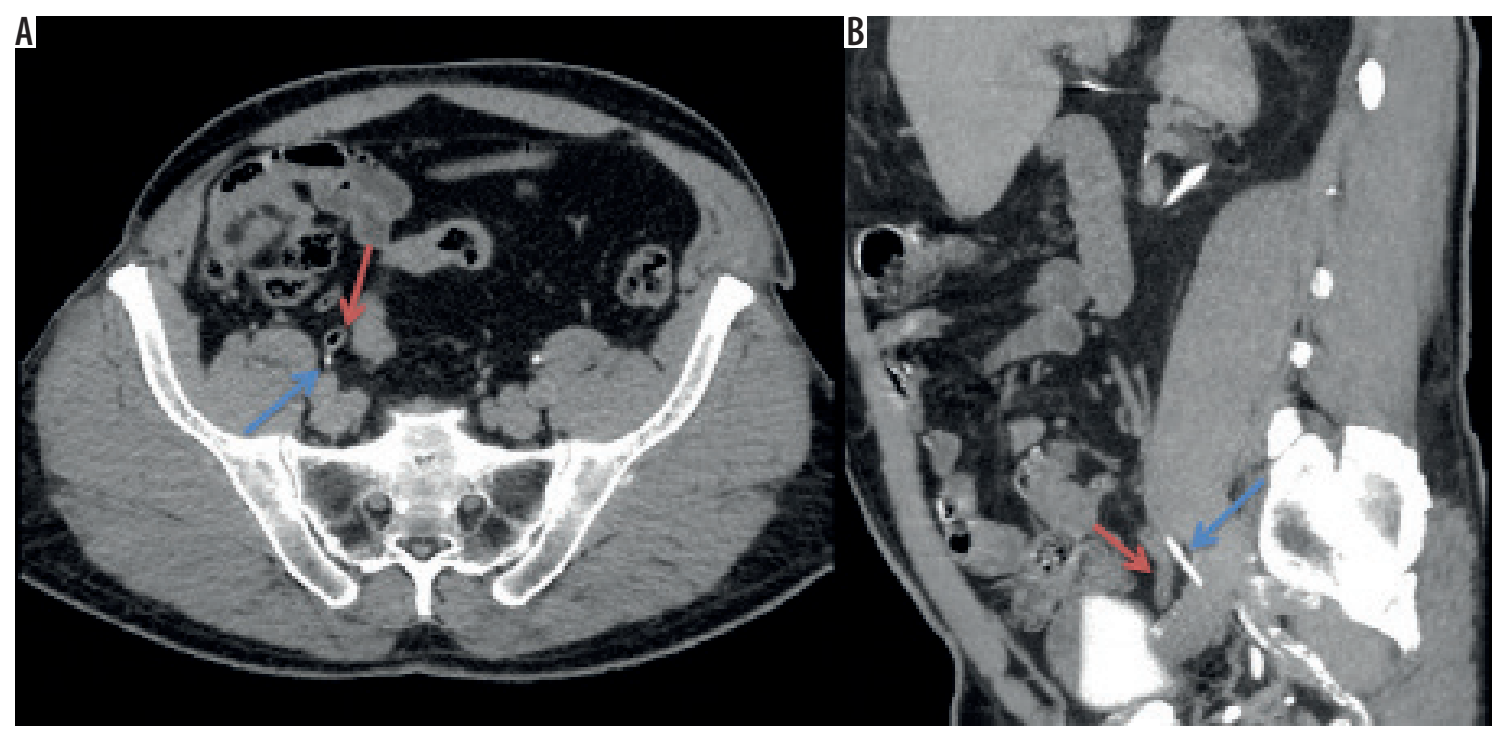

Figure 8. Axial CT scan (A) and sagittal CT reformation (B) in the late phase of a patient with a 15-cm-long, pelvic situated vermiform appendix (red arrow), which crosses the right ureter (blue arrow)

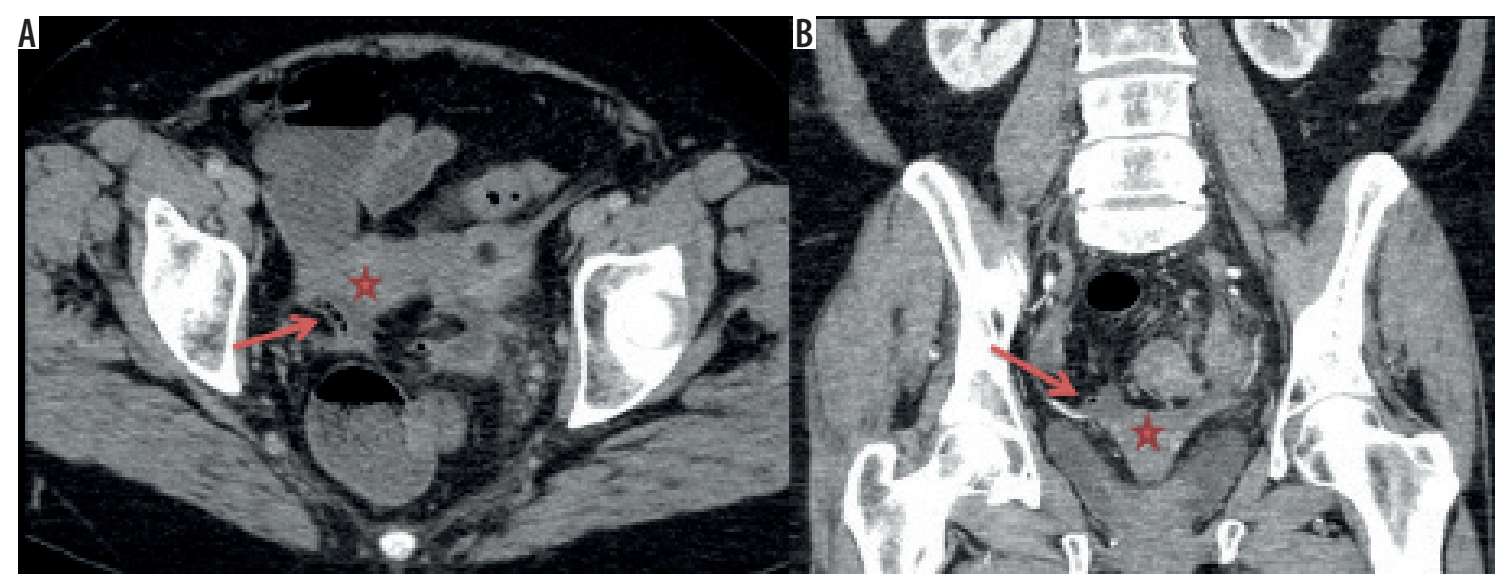

Figure 9. Axial CT scan (A) and coronal CT reformation (B) of a 68-year-old woman with an 8.1-cm-long pelvic vermiform appendix (arrows), whose distal part is located near to the right appendages and the right aspect of the uterus (star) 


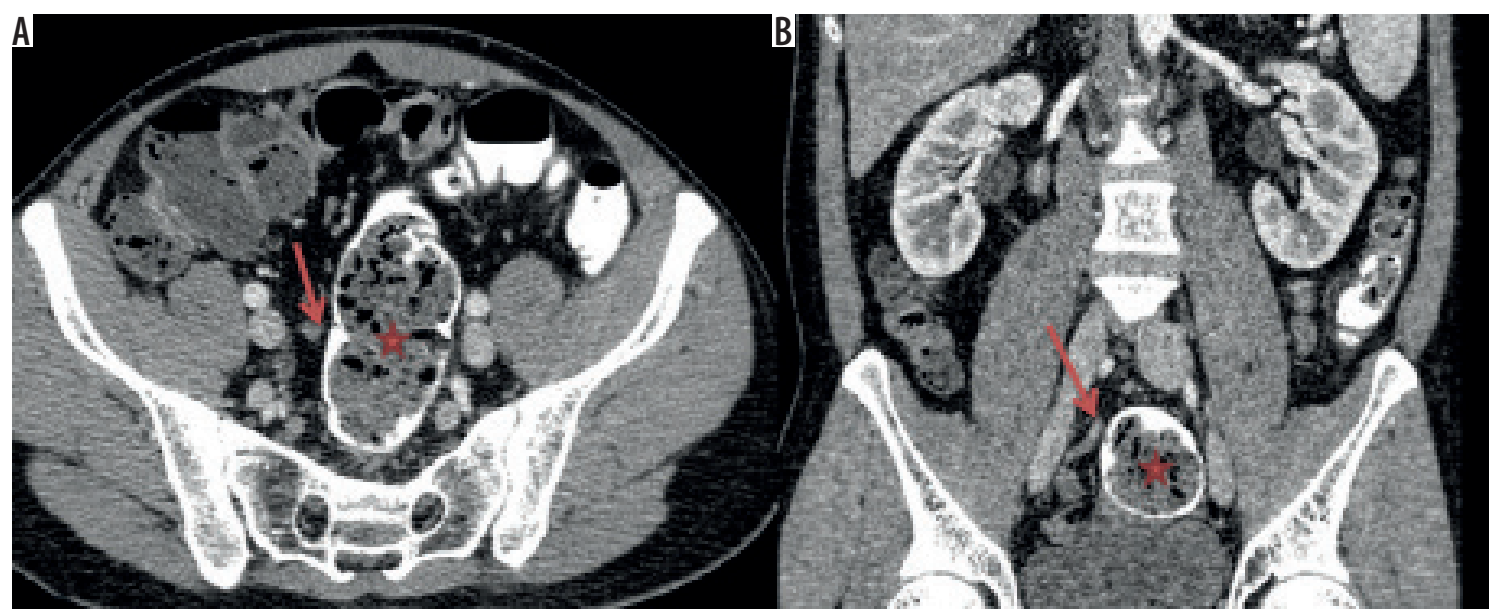

Figure 10. Axial CT scan (A) and coronal CT reformation (B) of a patient with the caecum located low in the pelvis (not shown) and with an 8.5- $\mathrm{cm}$-long postileal vermiform appendix (arrow), whose tip is situated next to the wall of the rectum (star)

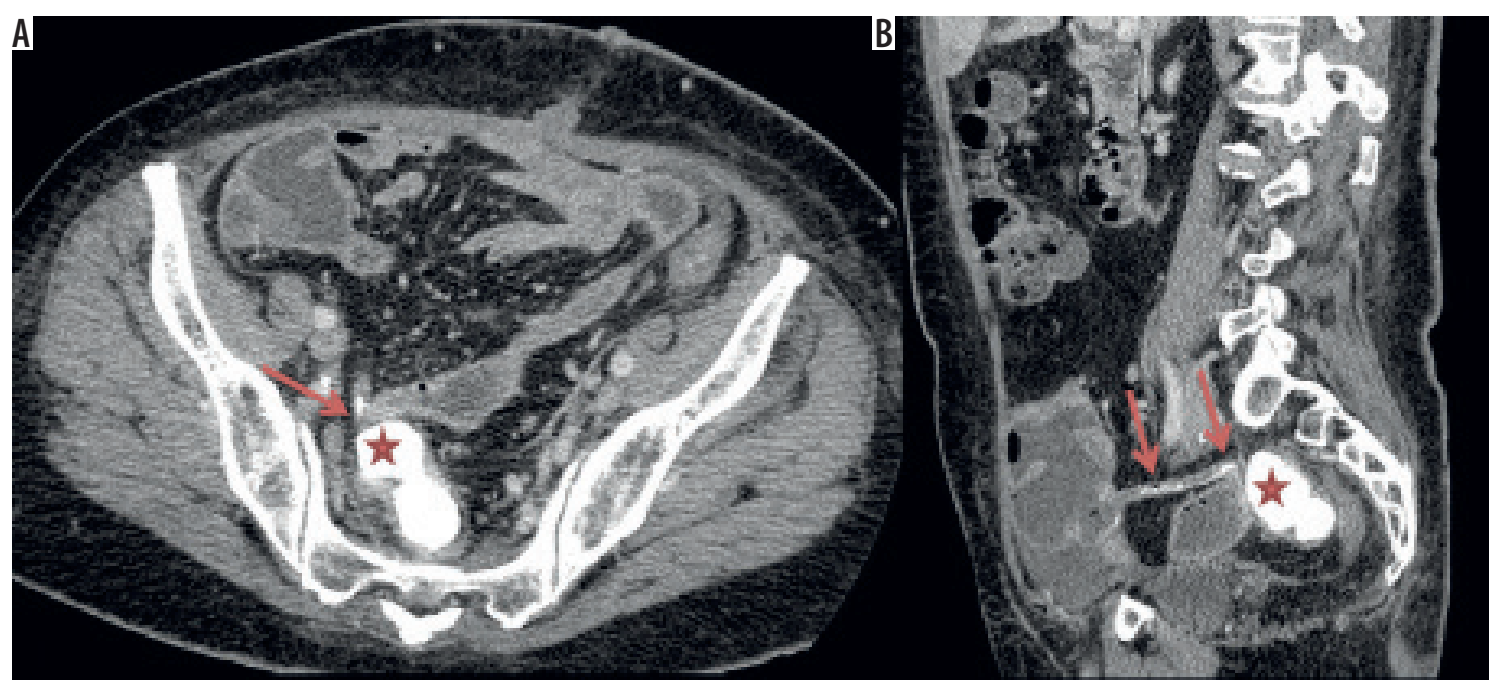

Figure 11. Axial CT scan (A) and sagittal CT reformation (B) of a patient with a short (approximately $6.4 \mathrm{~cm}$ ) vermiform appendix (arrow) in the retrocaecal position, whose tip is located next to the wall of the rectum (star)

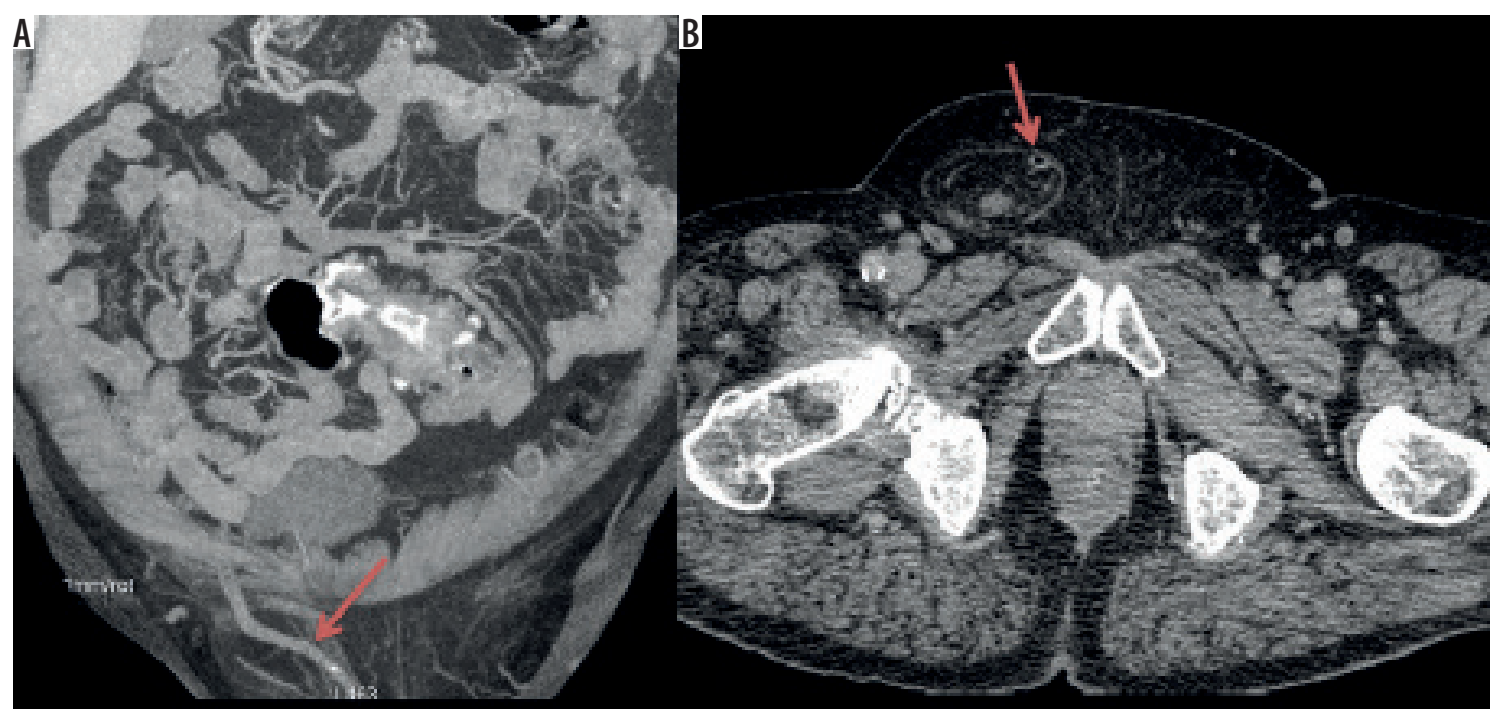

Figure 12. Sagittal CT reformation (A) and axial CT scan (B) of a patient with a very long (at least $16.7 \mathrm{~cm}$, partially out of the scope of the examination) pelvic vermiform appendix (arrow) as the content of a scrotal hernia 


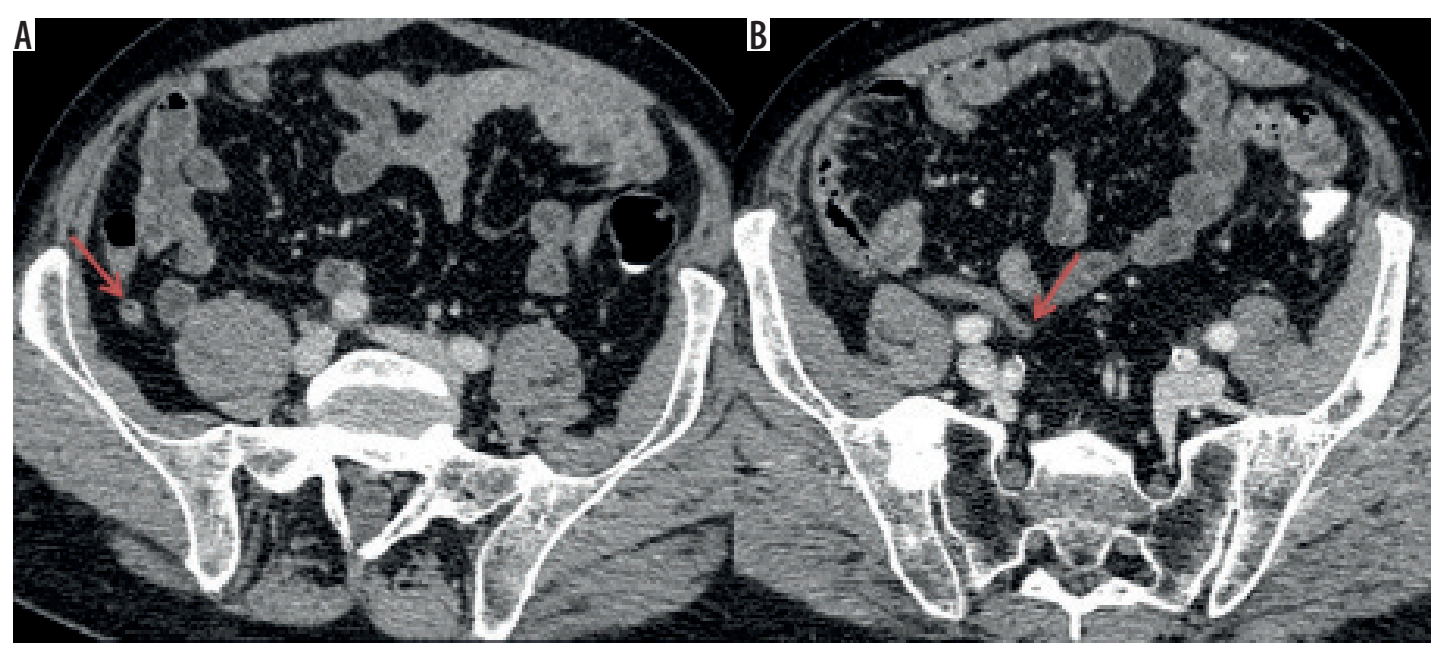

Figure 13. Axial CT scans of a patient before (A) and after (B) prostatectomy - the initial location of the vermiform appendix was subcaecal (A, arrow), when after prostatectomy it changed into pelvic, crossing the right ureter ( $B$, arrow)

migrates to the right iliac fossa in the course of the disease [7]. Symptoms like fever, vomiting, and elevated inflammation laboratory markers are usually observed subsequently to the pain [5]. In cases of atypically located tip of the appendix the pain is localised in areas of the abdomen typical for other diseases and leads to a clinical dilemma $[3,4,8,14,15]$. A possible misdiagnosis may lead to complications including perforation, abscess, and peritonitis $[3,7,16]$.

Ultrasound is usually the first-line imaging method in evaluation of patients with acute abdominal pain to confirm or exclude different conditions like cholecystitis and renal colic with hydronephrosis. However, it often may be helpful in establishing diagnosis of acute appendicitis, particularly in the typical pelvic position in the right iliac fossa, especially in children and during pregnancy $[13,15,17]$. It should be stressed that using ultrasound first instead of CT allows unnecessary exposure to radiation and iodine-based contrast media to be avoided [17,18].

Computed tomography is proposed only when ultrasonography is inconclusive; it is a very reliable modality in the assessment of the inflamed appendix in any location, and it allows exclusion of appendicitis by identification of the normal appendix $[12,15,19,20]$. Currently, it is being discussed whether non-enhanced CT (NECT) may suffice in as much as $75 \%$ of patients suspected of appendicitis and whether contrast-enhanced CT may be reserved for indecisive NECT, which may significantly reduce radiation dose and risk related to contrast media usage as well [21-23]. The acknowledged features of appendicitis in CT include an appendiceal diameter more than $6.5 \mathrm{~mm}$, inflammation of periappendiceal fat, surrounding fluid, and the presence of appendicolith [19].

MRI is reserved for children and pregnant women as a second-line method [13].

\section{Atypical appendicitis}

The knowledge of anatomical variants of the vermiform appendix has particular meaning for surgeons and may lead to a proper extension of a typical muscle-splitting incision $[1,2,5]$; therefore, in our opinion it seems to be important to report the position of an atypically located vermiform appendix as a $\mathrm{CT}$ finding.

In the literature there are a lot of case reports concerning clinically atypical appendicitis induced by anatomical variants of the length and/or position the vermiform appendix. Left-sided appendicitis in patients with midgut malrotation or situs inversus may be misinterpreted as acute diverticulitis, and both of these entities are followed by a raised white cell count and $\mathrm{C}$ reactive protein concentration $[15,24]$. Subhepatically located appendicitis can be clinically indistinguishable from cholecystitis, liver abscess, right renal colic, or pyelonephritis $[5,8,9,20]$. Inflammation of the tip of the appendix situated near the wall of the duodenum may produce symptoms of duodenitis or a duodenal ulcer. A long appendix crossing the right ureter can cause hydronephrosis with renal colic symptoms due to inflammation or the development of an abscess pressing the ureter [16]. When the appendix crosses the ileum or is situated in the midline, appendicitis may be indistinguishable from enteritis [3]. Appendicitis in women should be also differentiated with gynaecological pathologies like inflammation of the adnexa, torsion of the ovary, or extrauterine pregnancy [15]. Sometimes a long pelvic vermiform appendix is found in the contents of a scrotal hernia; therefore, in the case of appendicitis it may produce symptoms similar to orchitis or torsion of the testis [25]. A summary of possible misdiagnoses depending on the atypical location of the appendix is depicted on Table 1 .

\section{Conclusions}

The location of the appendix is variable due to the changeable length of the appendix and caecum position. Computed tomography is a very good method in depicting very unusual locations even of the unaffected vermiform appendix. 
Table 1. Atypical appendix locations and possible misdiagnoses

\begin{tabular}{|l|l|}
\hline Atypical appendix location & Possible misdiagnosis \\
\hline left lower quadrant & diverticulitis \\
\hline subhepatic & cholecystitis, liver abscess \\
\hline perirenal & renal colic, pyelonephritis \\
\hline periduodenal & duodenitis, duodenal ulcer \\
\hline ureter-crossing & renal colic (hydronephrosis) \\
\hline ileum-crossing & enteritis \\
\hline periadnexal & $\begin{array}{l}\text { inflammation, torsion of the ovary, } \\
\text { extrauterine pregnancy }\end{array}$ \\
\hline scrotal hernia & orchitis, torsion of the testis, incarceration \\
\hline
\end{tabular}

Clinicians and radiologists should be aware of atypical symptoms of appendicitis that result from the variable length and location of the appendix, which may help to avoid misdiagnosis and minimise the delay in applying the proper treatment.

\section{Compliance with ethical standards}

Ethical approval: All procedures performed in studies involving human participants were in accordance with the ethical standards of the institutional and/or national research committee and with the 1964 Helsinki Declaration and its later amendments or comparable ethical standards. For this type of study formal consent is not required.

\section{Conflict of interest}

The authors report no conflict of interest.

\section{References}

1. Schumpelick V, Dreuw B, Ophoff K, Prescher A. Appendix and cecum. Embryology, anatomy, and surgical applications. Surg Clin North Am 2000; 80: 295-318.

2. Mwachaka P, El-Busaidy H, Sinkeet S, Ogeng'o J. Variations in the position and length of the vermiform appendix in a black kenyan population. ISRN Anat 2014; 2014: 871048.

3. Cilindro de Souza S, Rodrigues da Costa SRM, Silva de Souza GI. Vermiform appendix: positions and length - a study of 377 cases and literature review. J Coloproctology 2015; 35: 212-216.

4. Ahmed I, Asgeirsson KS, Beckingham IJ, Lobo DN. The position of the vermiform appendix at laparoscopy. Surg Radiol Anat 2007; 29: 165-168.

5. Alzaraa A, Chaudhry S. An unusually long appendix in a child: a case report. Cases J 2009; 2: 7398.

6. Wakeley CP. The position of the vermiform appendix as ascertained by an analysis of 10,000 cases. J Anat 1933; 67: 277-283.

7. Ghorbani A, Forouzesh M, Kazemifar AM. Variation in anatomical position of vermiform appendix among Iranian population: an old issue which has not lost its importance. Anat Res Int 2014; 2014: 313575.

8. Ting JY, Farley R. Subhepatically located appendicitis due to adhesions: a case report. J Med Case Rep 2008; 2: 339.

9. Nayak SB, George BM, Mishra S, et al. Sessile ileum, subhepatic cecum, and uncinate appendix that might lead to a diagnostic dilemma. Anat Cell Biol 2013; 46: 296-298.

10. Malik RA, Mir SH, Feroz I, et al. An unusual case report - longest appendix in India $(20.5 \mathrm{~cm})$. Oncol Gastroenterol Hepatol Reports 2013; 2: 45-47.

11. Yabunaka K, Katsuda T, Sanada S, Fukutomi T. Sonographic appearance of the normal appendix in adults. J Ultrasound Med 2007; 26: $37-43$.

12. Kim HC, Yang DM, Jin W. Identification of the normal appendix in healthy adults by 64 -slice MDCT: The value of adding coronal reformation images. Br J Radiol 2008; 81: 859-864.

13. Deshmukh S, Verde F, Johnson PT, et al. Anatomical variants and pathologies of the vermix. Emerg Radiol 2014; 21: 543-552.
14. Kim S, Lim HK, Lee JY, et al. Ascending retrocecal appendicitis: clinical and computed tomographic findings. J Comput Assist Tomogr 2006; 30: 772-776.

15. Evrimler S, Okumuser I, Unal N. Computed tomography (CT) findings of a diagnostic dilemma: atypically located acute appendicitis. Pol J Radiol 2016; 81: 583-588.

16. Okur SK, Koca YS, Yıldız İ, Barut İ. Right hydronephrosis as a complication of acute appendicitis. Case Rep Emerg Med 2016; 2016: 3231862 .

17. Wu J, Zhang T, Zhu Y, Gong N. Diagnostic value of ultrasound compared to CT in patients with suspected acute appendicitis. Int J Clin Exp Med 2017; 10: 14377-14385.

18. Mostbeck G, Adam EJ, Nielsen MB, et al. How to diagnose acute appendicitis: ultrasound first. Insights Imaging 2016; 7: 255-263.

19. Vaghela K, Shah B. Diagnosis of acute appendicitis using Clinical Alvarado Scoring System and Computed Tomography (CT) Criteria in patients attending Gujarat Adani Institute of Medical Science a retrospective study. Pol J Radiol 2017; 82: 726-730.

20. Abougabal AM, Hafez A, Kasem MI. Role of multidetector computed tomography (MDCT) in diagnosis of subhepatic appendicitis. Egypt J Radiol Nucl Med 2012; 43: 347-352.

21. Tamburrini S, Brunetti A, Brown M, et al. Acute appendicitis: diagnostic value of nonenhanced CT with selective use of contrast in routine clinical settings. Eur Radiol 2007; 17: 2055-2061.

22. Chiu YH, Chen JD, Wang SH, et al. Whether intravenous contrast is necessary for CT diagnosis of acute appendicitis in adult ED patients? Acad Radiol 2013; 20: 73-78.

23. Hlibczuk V, Dattaro JA, Jin Z, et al. Diagnostic accuracy of noncontrast computed tomography for appendicitis in adults: a systematic review. Ann Emerg Med 2010; 55: 51-59.e1.

24. Çağlar E, Aribaş B, Tiken R, Keskin S. Midgut malrotation presenting with left-sided acute appendicitis and CT inversion sign. BMJ Case Rep 2014; pii: bcr2013202709.

25. Meinke AK. Review article: appendicitis in groin hernias. J Gastrointest Surg 2007; 11: 1368-1372. 